\title{
Education technology based on a 3D model of house VirTec
}

\author{
Daiva Makutėnienė ${ }^{1}$, Olga Ovtšarenko², Elena Safiulina ${ }^{2}$, Edgaras Timinskas ${ }^{1}$ \\ ${ }^{1}$ Department of Engineering graphics Faculty of Fundamental Sciences, Vilnius Gediminas \\ Technical University, Lithuania, ${ }^{2}$ Centre for Sciences, TTK University of Applied Sciences, \\ Estonia.
}

\begin{abstract}
In modern teaching, it is necessary to use modern technological achievements to involve students in the learning process, to create and constantly develop interesting and relevant teaching materials.

Educational materials in a playful form have the appropriate qualities. Game effects are associated with user participation in the interactive process and provide a high interest in the information offered. Getting feedback in the gameplay is not only an indicator of the success of the educational process but also a guide in the step-by-step movement of the student in the learning process.
\end{abstract}

Simulators of different objects are effective educational material that is available to students, contains the necessary information and functions, is simple and intuitive to use. This article provides an overview of different simulators with the study of the impact of their use on the effectiveness of the educational process.

One of the simulators is created in the teamwork of the project "Development of a virtual learning environment in technical higher education" (VirTec, 2018), funded by the Erasmus program for 24 months, which includes organizations from four countries: Estonia, Lithuania, Poland, Turkey, and Croatia.

Keywords: Virtual Learning Environment, Engineering Education, Simulator, Digihouse, Life-Long Learning, First-Year Student, Construction Specialties. 


\section{Introduction}

Rapidly developing technologies, fast information transfer, competition requires a new approach to planning and conducting the education process. Students are interested in the learning process, which is interactive, which you need not only to listen to but also to analyze, summarize and evaluate the information received.

Simulators of different objects are effective educational material that is available to students, contains the necessary information and functions, is simple and intuitive to use. This article provides an overview of different simulators with the study of the impact of their use on the effectiveness of the educational process.

One of the simulators is created in the teamwork of the project. It aims to create a digital house simulator and a set of training materials for construction specialities freshmen. The tasks of this simulator are to allow a learner to independently obtain knowledge about the details of the structure through the internet without special equipment.

The main objective of the project is to conduct a virtual learning environment on the base of the component parts of the house and its various modifications in order to increase interest and support the participation of students who has no experience in construction industry. Using the latest modelling technologies and graphic technologies allow to present more modern virtual models in training, which increases the visibility and interactivity of training materials.

\section{Background}

Educational technology is the use of both physical hardware, software, and educational theory to facilitate learning and improving performance by creating, using, and managing appropriate technological processes and resources. Every subject seeks the conceptual structure of the simulation in different ways. Innovative materials and new tools for teaching, educational technologies grow on many years. From the time when the first game Space War was developed by Steve Russell at the Massachusetts Institute of Technology, games have a massive growth (Jayakanthan, 2002). Implementation of simulation games in civil engineering education has shown encouraging results where the students learned various skills including management, engineering cost control, and teamwork (Scott et al. 2004). That is very important in the new era of BIM (Building information modelling) implementation to the construction industry. Computer simulation, refined graphics and multi-media can be developed to present engineering topics in ways that are not possible within the limitations of the traditional lecture format. Using animations, graphics, and an interactive environment, the instructional media can be designed to engage and stimulate students to effectively explain and illustrate course topics, and to build problem-solving skills 
(Deshpande \& Huang, 2011). Simulations, serious games and role-play activities can be useful tools to develop student-centred and problem-based learning environments because these activities allow students to apply their knowledge, skills and strategies practically while representing specific roles (Gradler, 2004). Every subject needs the structure of the simulation differently. For example, economists use a typically mathematical structure, for social education in the conceptual structure might be sets of social interactions. To civil engineers, the conceptual structure is often based on mathematical, physical and constructive elements. Computer models require that students complete several assignments taking a significant time. Simulations may be conducted with computers, pencil-and-paper, or physical models of constructions.

\subsection{Simulators in education}

The idea of using a computer simulation or management game to help students learn about complex issues is not new. Gilgeous and D’Cruz (1996) describe games stretching back over many years. The use of management games for teaching and learning about project planning and control is also not new and was described by Scott and Cullingford in 1973. Different simulators were developed over the years. Simulations are models where the student participate in a space defined by the teacher. They represent a reality within which students interact. The teacher controls the parameters of that space and uses it to achieve the desired instructional results. A simulation is a form of experiential learning. A simulation is a mix of model elements, game and instruction parts. There are a large number of custom and very specialized simulations, there are also many simulators which can run an infinite number of models. Examples are MATLAB Simulink (engineering and manufacturing), ANSYS (engineering), Gazebo (robotics), etc. (Simulators: The Key Training Environment for Applied Deep Reinforcement Learning, Cyrill Glockner).

Learning simulations historically have fallen into two categories. There are educational simulations that follow the rigour and fidelity of flight simulators. And there are serious games, that follow the entertainment model of a SimCity. Civilization V is an example in Figure 1. The role that the player is put in has no real world counterpart. One of the best parts of a simulation is that you can learn rigorously and predictably without ever being taught anything. Students can customize some of their experience. Debriefing can subsequently make sure all is covered. No student learns everything presented in any medium. This is true of lectures, textbooks, sports drills, and apprenticeships. Clark Aldrich posited that the more students actively engage the material and see consequences good and bad that are based on their strategy and tactics, the greater the material does stick. 

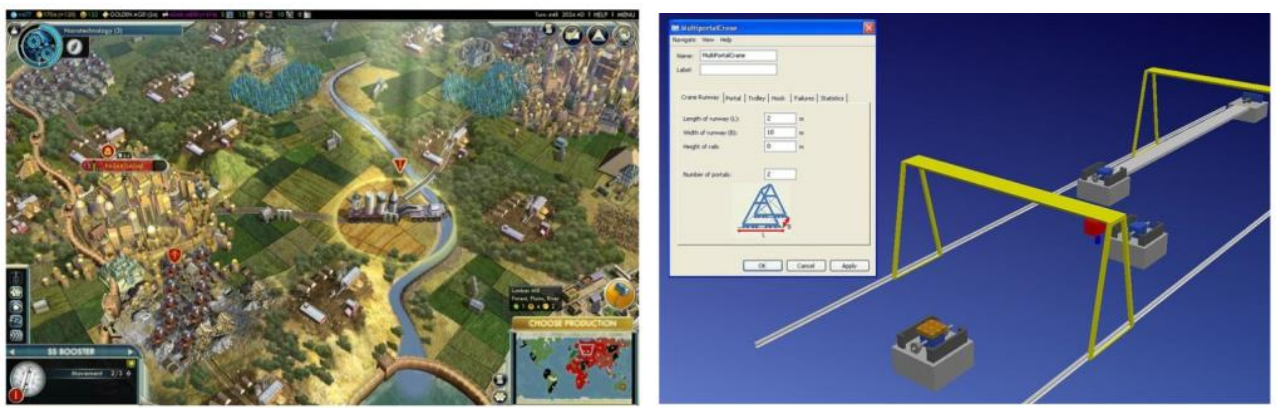

Figure 1. Application of simulation games in engineering education. Source: Deshpande and Huang. (2011).

For example, ForgeFX Simulations developing over 100 simulation training programs and applications, across many of different subjects and curricula, they help deliver digital learning products that transform students from passive audience members, to active participants in the learning process. The ForgeFX website includes information about their works. The realtime 3D wave simulator demonstrates the connection between wind speed and ocean particle motion depth. BeardedBrothers.games ask to become a motorcycle mechanic in Biker Garage, mechanic Simulator (Figure 2).
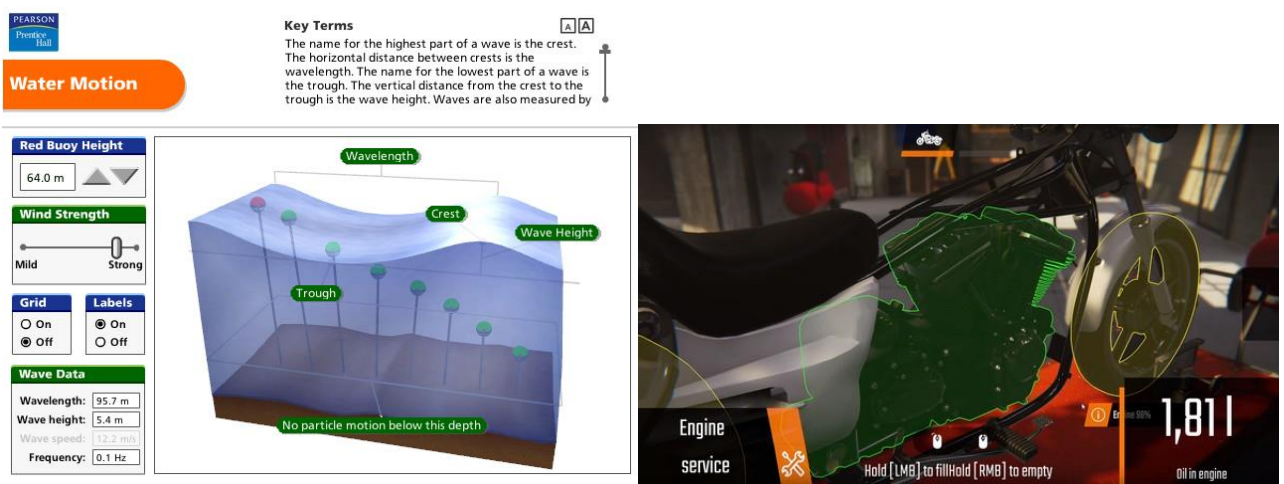

Figure 2. ForgeFX and BeardedBrothers.games simulators screenshots. Source: http://forgefx.com/, https://store.steampowered.com.

\subsection{Simulation in Engineering education}

In the academic environment, the Engineering teachers usually find students who have difficulties for solving tasks requiring spatial reasoning and viewing abilities. Deshpande and Huang (2011) posited that simulation games have been applied in various educational domains. Authors cited Au\&Parti suggested that computerized heuristic games could be used for the education of engineers and planners in the construction industry. Abou Rizk and Sawhney posited that they developed an Internet-based Interactive Construction Management Learning System (ICMLS) with a rich graphical user interface, Virtual Reality 
Modeling Language (VRML), and discrete-event simulation for construction management education. Crown developed many web-based games using simple JavaScript code to enhance visualization skills essential in engineering graphics. Taxonomy of simulation games application in engineering education is shown in Figure 3.

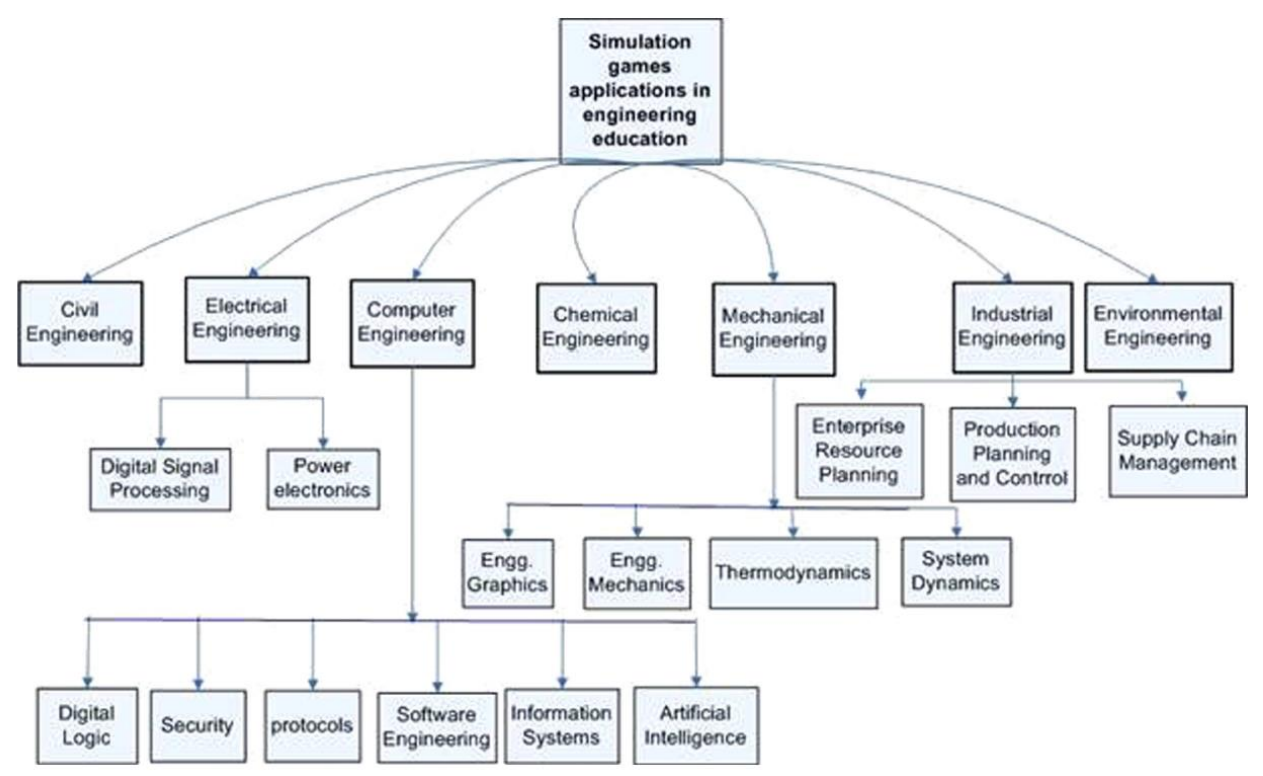

Figure 3. Application of simulation games in engineering education. Source: Deshpande and Huang (2011).

The new teaching methodology using simulation will transform the teacher's role to a "bringer" of knowledge as opposed to that of some agent in the common educational environment.

\section{3D model simulator VirTec}

Educational technology is the use of both physical hardware, software, and educational theoretic to facilitate learning and improving performance by creating, using, and managing appropriate technological processes and resources. The idea of the simulator' creating is the simplicity of its usage. A student does not need either the knowledge and skills of threedimensional modelling no the availability of a licensed program. A simulator has to be done as a web page that opens quickly and also quickly responds to user requests, having the same possibilities of turning, scaling, viewing an object in parts, and using cutting planes that provide specialized viewing software. In this article are presented the $3 \mathrm{D}$ model part of the project „Development of Virtual Learning Environment in Technical Higher Education“ (VirTec, 2018), which was co-founded by the Erasmus+ KA2 program and started from 
October 2018. The partners of the consortium are organizations from four countries: Estonia, Lithuania, Turkey, Poland and Croatia. To create educational material, it is necessary to take into account the general principles of teaching and learning design and above all what is planned to study, what are the goals / desired outcomes for students, what is a possible form of training material, what are abilities of control and evaluation of the knowledge gained, how to provide feedback to consolidate the material and create prerequisites for further development.

It aims to create a digital house and a set of educational materials for first-year students of construction specialities and for learners without knowledge about the construction industry to promote effective lifelong learning through simulation. The task of this simulation is to allow a learner to get knowledge with parts of construction by himself. Game form of learning, the possibility to test knowledge and register results, quick and independent assessment, feedback and recommendations - all this is provided by modern virtual technologies. For the modelling of the 3D house, TIMBECO LLC (timbeco.ee) drawings set of a near-zero energy small houses have been used. It is quite simple to use the simulator because it is equipped with a logical and user-friendly interface. On the viewing screen next to the model of the house, there is a menu indicating the parts of the building structure. The menu allows for choosing different parts of the house for detailed consideration: the foundation, stairs, wall, roof. Now functions of the simulator made it possible to use cutting planes - (horizontal and two vertical) to obtain cuts at the house. This opportunity is a great success for the project and provides students via the simulator' use to learn the basics of the constructions' structural components. And the expected effect of the simulator' use is a first acquaintance with the structures, materials, technologies, and the relative position of the elements in a user-friendly viewing mode. Also, one more important task of the simulator is to support an interest in the speciality and the desire to get solid professional knowledge. Based on the created 3D model, it is possible to prepare simulators for more complex objects, structures, or connection nodes.

Nowadays students seek to get new methodologies for studies. There are a lot of scientific works. Scientists are presenting a methodology to evaluate the use of personalised learning scenarios. High-quality learning scenarios should consist of the learning components (i.e. learning objects, learning activities, and learning environment) optimised to particular students according to their personal needs, e.g. learning styles (Kurilova et al. 2017). Authors of articles say, that future education means personalisation plus intelligence (Melesko \&Kurilovas, 2016). Analysis of students' preferences to certain learning styles according to Felder and Silverman Learning Styles Model (Felder \& Silverman, 1988) is widely recognised the most suitable for engineering disciplines and e-learning. Felder and Silverman learning styles model has four dimensions type. Each dimension shows a different aspect of learning with a linguistic variable. These dimensions as "sensing" or "intuitive" learners, as 
"visual" or "verbal" based on the way they receive information (virtual house), as "active" or "reflective" according to the way they process information (preparing of tasks), as "sequential" or "global" based on the way they understand information (Ciloglugil \& Inceoğlu, 2018).

Intelligent personalised learning using information technologies can provide better results for adaptivity and VirTec project result can be an attractive type of learning using intelligent IT tools.

In December 2018, pollmill.com conducted a survey of building teachers - colleagues from different countries - Estonia, Lithuania, Poland, Turkey, Finland. The purpose of the survey was to obtain information about their interest in using the virtual home simulator in teaching. Analysis of the processed data led to the conclusion that the high interest of collegues teachers of construction specialities to the virtual home simulator and confirmed the correctness of the project participants' intentions - to create a simulator that will fundamentally change the work of teachers and improve the quality of the learning process.
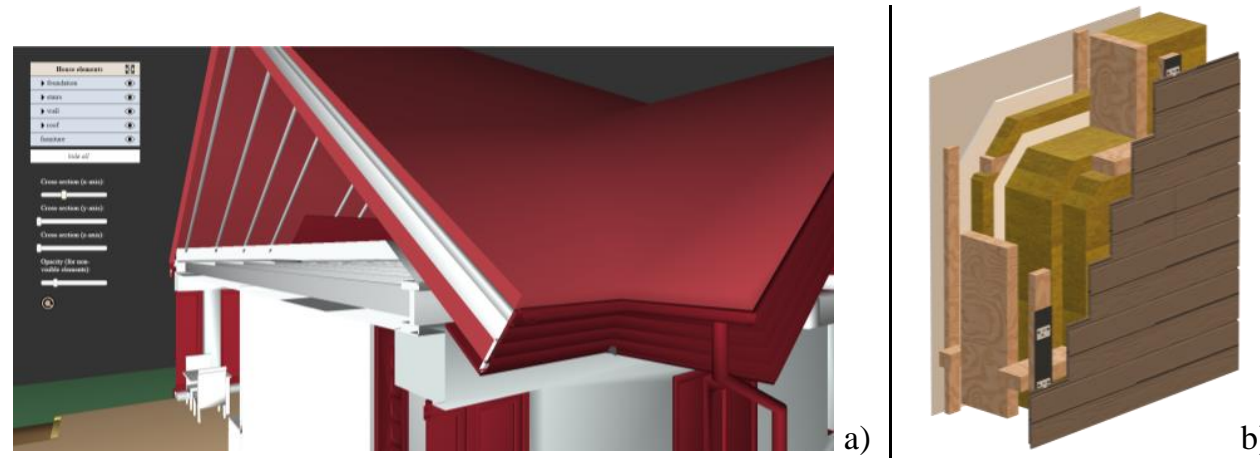

Figure 4. The main window of the simulator VirTec with vertical cutting (a), visualization of house and part of the wall (b). Source: VirTec, 2020.

\section{Conclusions}

Rapidly developing technologies, fast information transfer, competition requires a new approach to planning and conducting the education process. Students are interested in the learning process, which is interactive, which you need not only to listen to but also to analyze, summarize and evaluate the information received. Simulators of different objects are effective educational material that is available to students, contains the necessary information and functions, is simple and intuitive to use. One of the simulators is created in the teamwork of the project. It aims to create a digital house simulator and a set of training materials for construction specialities freshmen. The tasks of this simulator are to allow a learner to independently obtain knowledge about the details of the structure through the internet without 
special equipment. The use and development of simulation software will give new power for engineering education. It will also give satisfaction for students having the ability to work in inter-functional, individual and group environments. The simulator becomes a very useful assistant for students at the stage of primary vocational education, because it has all the functions of specialized programs for viewing a complex object: it is a free web page that loads very quickly into the gadget, opens without specialized programs (does not require a license) and is easy responds to user requests.

\section{References}

Aldrich, C. (2017, July 14). What's A Learning Simulation? Message posted to https://www.teachthought.com

AbouRizk, S. M. and Sawhney, A. (1994). Simulation and Gaming in Construction Engineering Education. ASEE/C2E2/C2EI Conference, Edmonton, Alberta, June 1994.

$\mathrm{Au}, \mathrm{T} .$, \& Parti, E. (1969). Building construction game - general description. Journal of the Construct Division 95 (1969), 1-9.

Ciloglugil, B., \& Inceoğlu, M. (2018). A Learner Ontology Based on Learning Style Models for Adaptive E-Learning. In Computational Science and Its Applications - ICCSA 2018, pp.199-212.

Crown S.W. (1999). Web-based learning: Enhancing the teaching of engineering graphics. Interactive Multimedia Electronic Journal of Computer Enhanced Learning 1(2). Retriewed from http://imej.wfu.edu/articles/1999/2/02/index.asp

Deshpande, A.A., \& Huang, S. H. (2011). Simulation games in engineering education: A state-of-the-art review, Computer Applications in Engineering Education, 19(3), 399410. doi.org/10.1002/cae.20323

Felder, R., \& Silverman, L. (1988) Learning and Teaching Styles in Engineering Education. Engineering Education, 78(7), 674-681. Retrieved from https://www.researchgate.net/publication/257431200_Learning_and_Teaching_Styles_i n_Engineering_Education

Gileous, V., \& DÇruz, M. (1996). A study of business and management games. Management Development Review, 9 (1), 32-40.

Gredler, M. E. (2004). Games and simulations and their relationships to learning. In D. H. Jonassen (Ed.), Handbook of research for educational communications and technology (2nd ed., pp. 571-82). Mahwah, NJ: Lawrence Erlbaum Associates.

Jayakanthan, R. (2002). Application of computer games in the field of education. The Electronic Library 20 (2), doi.org/10.1108/02640470210697471

Kurilova, J., Kurilovas, E., Minkevicius, S. (2017) Evaluation of suitability, acceptance and use of personalised learning scenarios. Proceedings of Lithuanian mathematics society. Vilnius. Ser. B, 45-50. Retrieved from https://www.mii.lt/LMR/B/2017/58B08.htm

Melesko, J., Kurilovas, E. (2016) Personalised intelligent multi-agent learning system for engineering courses. Conference: 4th Workshop on Advances in Information, Electronic and Electrical Engineering (AIEEE 2016). doi: 10.1109/AIEEE.2016.7821821 
Scott, D., Mawdesley, M., \& Al-Jibouri, S. H. S. (2004). The use and efficacy of a simulation model for teaching project control in construction. In P. S. H. Poh, A. D. Mackenzie, \& C. D. Katsanis (Eds.), World of construction project management. Proceedings of the $1 \mathrm{st}$ international conference (pp. 267-276). Toronto, Canada. 